\title{
Emerging Psychiatric Themes in Post-COVID-19 Patients on a Psychiatry Consultation-liaison Service
}

\author{
Samer El Hayek ${ }^{1}$ - Ghida Kassir² • Hussein Zalzale ${ }^{3}$ · Jairo M. Gonzalez-Diaz ${ }^{4,5,6}$. \\ Maya Bizri ${ }^{2}$
}

Accepted: 22 August 2021 / Published online: 31 August 2021

(c) The Author(s), under exclusive licence to Springer Science+Business Media, LLC, part of Springer Nature 2021

\begin{abstract}
The need for consultation-liaison psychiatry on COVID-19 wards has substantially increased since the start of the pandemic. In this cross-sectional study, we aimed to summarize the characteristics of patients admitted to the post-COVID-19 ward of the American University of Beirut Medical Center who received a psychiatric consultation. We collected relevant sociodemographic and medical data, information about past psychiatric history, psychiatry consultation details, hospital course, and disposition outcome. We also conducted chi-square and binary logistic regression analyses to assess the association between the different variables and disposition outcome. A total of 52 patients (mean age 57.33 years; equal gender distribution) were seen by the psychiatry consult-liaison team. Most had medical comorbidities and $21.2 \%$ required intubation. The most prevalent psychiatric diagnoses were delirium $(30.8 \%)$, major depressive episode (15.4\%), and other anxiety disorder (15.4\%). Pharmacological management was implemented in $90.4 \%$ of cases and mainly included second-generation antipsychotics (36.5\%). Non-pharmacological interventions consisted of those related to delirium and therapy for anxiety. Only intubation was significantly associated with disposition outcome $(p=0.004)$. This study highlights the various psychiatric themes emerging during the acute and post-acute periods of hospitalization for COVID-19. Hospitalized individuals recovering from the infection should be diligently screened and referred to the psychiatry consultation-liaison team to ensure the implementation of appropriate interventions.
\end{abstract}

Keywords COVID-19 $\cdot$ Psychiatry $\cdot$ Consultation-liaison $\cdot$ Inpatient $\cdot$ Delirium $\cdot$ Anxiety

Maya Bizri

Mb112@aub.edu.lb

1 Department of Psychiatry and Behavioral Sciences, University of Miami Miller School of Medicine, Miami, Florida, USA

2 Department of Psychiatry, American University of Beirut, Beirut, Lebanon

3 Faculty of Medicine, American University of Beirut, Beirut, Lebanon

4 UR Center for Mental Health - CERSAME, School of Medicine and Health Sciences, Universidad del Rosario, Bogota, Colombia

5 Clínica Nuestra Señora de La Paz, Bogota, Colombia

6 Barcelona Clínic Schizophrenia Unit, Neurosciences Institute, Barcelona University, Barcelona, Spain 


\section{Introduction}

Growing evidence suggests that the Coronavirus Disease 2019 (COVID-19) has increased the burden of mental disorders in the world [1,2]. Most of this evidence portrays the psychological impact of the pandemic on the general population and healthcare workers [3, 4]. In patients infected with COVID-19, a negative psychological impact has also taken its toll on their mental health. A study evaluating 40,469 affected outpatients noted that $22.5 \%$ had neuropsychiatric manifestations, including anxiety (4.6\%), mood (3.8\%), and sleep disorders (3.4\%) [5]. A recent study of 402 adults who surpassed COVID-19 infection found that $56 \%$ scored in the pathological range in at least one psychiatric clinical dimension one month following hospital treatment. This included post-traumatic stress, depression, insomnia, and anxiety. A significant risk factor for these patients was the presence of premorbid psychiatric illness [6]. Along the same lines, a literature review hypothesized that individuals who acquired COVID-19 infection, particularly those who had a severe illness course, may have a heightened risk of suicide [7].

Alternatively, little is known about psychiatric symptoms in patients hospitalized with postCOVID-19 complications and their treatment options [8]. One study postulated that the incidence of psychiatric sequelae would be $22 \%$ to $24 \%$ for post-traumatic stress, $26 \%$ to $33 \%$ for depression, and $38 \%$ to $44 \%$ for generalized anxiety when using data from patients with acute respiratory distress syndrome with intensive care unit admissions as a predictive model [9]. Such elevated incidence rates would also be expected in a prolonged hospital stay in the setting of COVID-19 infection.

Psychiatric symptoms and disorders developing in the acute and post-acute periods in patients hospitalized for COVID-19 may arise due to several factors. These include concerns about the repercussions of the disease [10], social isolation [11], and financial difficulties [12]. Nevertheless, psychological stress is not the only mechanism for emerging psychiatric manifestations following the infection. These symptoms can also occur either secondary to the direct effects of the virus on the central nervous system, the indirect activated immune-inflammatory responses, or the medications commonly provided for treatment [8,13-16]. Other factors can have a role in critically ill patients, such as sedation, organ failure, mechanical ventilation, and immobilization [17].

As such, the need for consultation-liaison psychiatry (CLP) on COVID-19 wards has substantially increased $[18,19]$. Indeed, in many hospitals, staff assigned to the CLP have been taking over the management of psychiatric complications in inpatients infected or recovering from the virus [18].

Taking the preceding statements into account, this cross-sectional study aimed to quantify the characteristics, psychiatric symptomatology, and treatments of patients hospitalized at the post-COVID-19 ward of the American University of Beirut Medical Center (AUBMC) and on whom the CLP team was consulted. A further objective of this study was to identify potential predictors of discharge in this patient population.

\section{Methods}

\section{Study Design and Setting}

We conducted a retrospective cross-sectional study on inpatients admitted to the postCOVID-19 unit of the AUBMC, an urban tertiary care center in Lebanon. The study was approved by the Institutional Review Board committee of the institution (BIO-2021-0095). 


\section{Study Population}

We considered patients eligible if they:

- were adults aged 18 years and above

- were admitted between 3 February 2020 and 23 February 2021

- had an official CLP referral.

Patients were typically admitted or transferred to the post-COVID-19 unit if they had a COVID-19 infection documented on polymerase chain reaction (PCR) analysis of nasopharyngeal swab specimen and followed by a negative PCR test, or if 14 days elapsed since the start of their symptoms, whichever occurred first. The post-COVID-19 unit, therefore, encompassed patients with acute (up to 4 weeks from the onset of symptoms) and postacute (4 to 12 weeks from the onset of symptoms) COVID-19 infection [20].

\section{Data Extraction}

We retrieved and collected data from patients' Electronic Health Records available on the EPIC Systems at AUBMC. Study outcomes consisted of patients' demographics (age, gender, and marital status), information related to the psychiatric consultation (time of consultation, the reason for referral, psychiatric symptoms on assessment, diagnosis as per Diagnostic and Statistical Manual of Mental Disorders, 5th Edition (DSM-5), and implemented pharmacological and non-pharmacological interventions), other pertinent psychiatric information (past psychiatric history, past psychiatric medications, family history of mental illness), medical comorbidities, course of COVID-19 infection (intensive care requirement during hospitalization, intubation during hospitalization, and receipt of COVID-19 medications), the total length of hospital stay, and outcome at discharge (discharge home, death, or transfer to a chronic care facility).

\section{Statistical Analysis}

We presented descriptive data using absolute numbers and percentages for categorical variables and means with standard deviations for continuous variables. We conducted a Pearson chi-square analysis to examine the associations between our variables and disposition outcome (death versus discharge or transfer to a chronic care facility). We then performed a binary logistic regression for significant associations. For the sake of analysis, antidepressants and antipsychotics were grouped into one variable. A $p$-value of less than 0.05 was used to indicate statistical significance. All data analysis was performed using the Statistical Package for the Social Sciences (SPSS for Windows, version 26.0. SPSS Inc., Chicago, IL, USA).

\section{Results}

Case records of 52 patients seen by the CLP team were retrieved. Table 1 shows their sociodemographic and medical characteristics. The sample consisted of 24 males (46.2\%) and 28 females $(53.2 \%)$ and had a mean age of 57.33. About two-thirds of patients $(69.2 \%)$ 
Table 1 General sociodemographic and medical characteristics of patients seen by the psychiatry consultation-liaison team on the post-COVID-19 unit

\begin{tabular}{lll}
\hline Variable & Count & \\
\hline & Mean \pm Standard deviation & \\
Age (years) & $57.33 \pm 21.64$ & \\
Length of hospital stay (days) & $29.52 \pm 55.45$ & \\
Gender & Frequency (percentage) & \\
Marital status & Male & $24(46.2 \%)$ \\
& Single & $10(19.2 \%)$ \\
& Married & $36(69.2 \%)$ \\
Medical comorbidity & Divorced & $2(3.8 \%)$ \\
& Widowed & $4(7.7 \%)$ \\
& Cardiac & $32(61.5 \%)$ \\
& Pulmonary & $15(28.8 \%)$ \\
& Infectious (not COVID-19) & $20(38.5 \%)$ \\
Gastrointestinal & $5(9.6 \%)$ \\
Intubation & Neurological & $8(15.4 \%)$ \\
COVID-19 treatment & Oncological & $13(25 \%)$ \\
& Other systems & $15(28.8 \%)$ \\
& 21 (40.4\%) & \\
Discharge outcome & 11 (21.2\%) & \\
& Steroids & $33(63.5 \%)$ \\
& Convalescent plasma & $15(28.8 \%)$ \\
& Tocilizumab & $15(28.8 \%)$ \\
& Remdesivir & $16(30.8 \%)$ \\
& Ivermectin & $18(34.6 \%)$ \\
& Antibiotics & $33(63.5 \%)$ \\
& Discharge home & $34(65.4 \%)$ \\
& Death & $16(30.8 \%)$ \\
& Transfer to a chronic facility & $2(3.8 \%)$ \\
\hline & &
\end{tabular}

were married. The mean length of hospitalization was 29.52 days. Most patients had medical comorbidities; almost half $(40.4 \%)$ required admission to the intensive care unit and about one-quarter $(21.2 \%)$ were intubated throughout their stay. The most commonly received treatments for COVID-19 infection included steroids and antibiotics $(63.5 \%$ of the sample received both). About one-third (30.8\%) passed away. Further information is detailed in Table 1.

The characteristics of the psychiatry liaison team consultations are depicted in Table 2 . The mean time for a psychiatry consult was 13 days from admission. Agitation/rule out delirium (36.5\%), anxiety/panic attacks (30.8\%), and low mood (25\%) were the most common reasons for the consult of the primary team. The most prevalent DSM-5 diagnoses were delirium (30.8\%), major depressive episode (15.4\%), and other anxiety disorder (15.4\%). Almost half of the participants $(46.2 \%)$ had a past psychiatric history. About one-third (36.5\%) received a psychotropic medication before hospitalization and $21.2 \%$ had a positive family history of mental illness. Pharmacological management was implemented in $90.4 \%$ of cases and mainly included second-generation antipsychotics $(36.5 \%)$ and selective serotonin reuptake inhibitors 
Table 2 Characteristics of the psychiatry-liaison team consultations received by patients on the postCOVID-19 unit

\begin{tabular}{|c|c|c|}
\hline Variable & Count & \\
\hline & Mean \pm Standard deviation & \\
\hline Day to psychiatry consult & $13 \pm 21.51$ & \\
\hline & Frequency (percentage) & \\
\hline Reason for a psychiatry consult & Low mood & $13(25 \%)$ \\
\hline & Suicidality & $4(7.7 \%)$ \\
\hline & Anxiety/Panic attacks & $16(30.8 \%)$ \\
\hline & Agitation/Delirium & $19(36.5 \%)$ \\
\hline Psychiatric symptoms present on assessment & Depressive symptoms & $26(50 \%)$ \\
\hline & Suicidality & $20(38.5 \%)$ \\
\hline & Anxiety symptoms & $35(67.3 \%)$ \\
\hline & Panic symptoms & $11(21.2 \%)$ \\
\hline & Somatic symptoms & $2(3.8 \%)$ \\
\hline & Drug-related symptoms & $5(9.6 \%)$ \\
\hline & Delirium-related symptoms & $16(30.8 \%)$ \\
\hline & Trauma-related symptoms & $2(3.8 \%)$ \\
\hline DSM-5 diagnosis as per the consulting team & Major depressive episode & $8(15.4 \%)$ \\
\hline & Other mood disorder & $6(11.5 \%)$ \\
\hline & Adjustment disorder & $2(3.8 \%)$ \\
\hline & Panic attack/disorder & $3(5.8 \%)$ \\
\hline & Generalized anxiety disorder & $1(1.9 \%)$ \\
\hline & Other anxiety disorder & $8(15.4 \%)$ \\
\hline & Delirium & $16(30.8 \%)$ \\
\hline & Drug intoxication/withdrawal & $7(13.5 \%)$ \\
\hline & Serotonin syndrome & $2(3.8 \%)$ \\
\hline & Normal reaction to stress & $1(1.9 \%)$ \\
\hline Pharmacological management & Selective serotonin reuptake inhibitor & $8(15.4 \%)$ \\
\hline & Atypical antidepressant & $5(9.6 \%)$ \\
\hline & Tricyclic antidepressant & $1(1.9 \%)$ \\
\hline & $1^{\text {st }}$ generation antipsychotic & $5(9.6 \%)$ \\
\hline & $2^{\text {nd }}$ generation antipsychotic & $19(36.5 \%)$ \\
\hline & Benzodiazepine & $4(7.7 \%)$ \\
\hline & Cyproheptadine & $2(3.8 \%)$ \\
\hline & Lithium/mood stabilizer & $2(3.8 \%)$ \\
\hline & Melatonin & $2(3.8 \%)$ \\
\hline & Stimulant & $1(1.9 \%)$ \\
\hline & None & $5(9.6 \%)$ \\
\hline Non-pharmacological management & Management of delirium & $16(30.8 \%)$ \\
\hline & Referral to therapy & $7(13.5 \%)$ \\
\hline & Referral to social services & $1(1.9 \%)$ \\
\hline & Suicide precautions & $4(7.7 \%)$ \\
\hline & None & $24(64.2 \%)$ \\
\hline Past psychiatric history & $24(46.2 \%)$ & \\
\hline Previous psychotropic medications & $19(36.5 \%)$ & \\
\hline Psychiatric family history & $11(21.2 \%)$ & \\
\hline
\end{tabular}


(15.4\%). Non-pharmacological interventions encompassed those targeting delirium (30.8\%), referral to therapy $(13.5 \%)$ or social services $(1.9 \%)$, and suicide precautions $(7.7 \%)$. Restraints were never recommended or used.

Chi-square analysis revealed a signficant association between death as disposition outcome and past psychiatric history $(\chi 2(1)=6.98 ; p=0.008)$, intensive care unit admission $(\chi 2(1)=11.50$; $p<0.001)$, intubation $(\chi 2(1)=11.53 ; p=0.002)$, antipsychotic treatment $(\chi 2(1)=4.74 ; p=0.029)$, treatment with convalescent plasma $(\chi 2(1)=5.04 ; p=0.044)$, treatment with remdesivir $(\chi 2(1)=7.04 ; p=0.020)$, treatment with ivermectin $(\chi 2(1)=4.48 ; p=0.029)$, and treatment with antibiotics $(\chi 2(1)=5.28 ; p=0.016)$. Additionaly, the association between disposition outcome and past medical history of cardiac disease was marginally signficant $(\chi 2(1)=3.79 ; p=0.051)$. Only intubation remained significant in the binary logistic regression $(p=0.004)$.

\section{Discussion}

In this study, we summarize cases seen by the CLP service on a post-COVID-19 unit. To the best of our knowledge, similar studies focus on the acute, rather than post-acute, period of the infection. Thus, we highlight the vulnerability of patients in both the acute and postacute periods of hospitalization for COVID-19.

Most reasons for consulting the psychiatry team were low mood, anxiety and panic, and delirium-related symptoms such as aggression and disorientation. In general, the identified reasons for requesting a consult did not diverge from those of recent studies conducted on COVID-19 wards [21, 22]. However, one study by Arbelo et al. had psychiatric drug dose adjustment as the most common reason for psychiatry referral (38.8\%) [23]. This can be explained by the large number of participants who had one previous psychiatric diagnosis (74.6\% compared to $46.2 \%$ in our sample) and were taking at least one psychiatric drug (63.4\% compared to $36.5 \%$ in our sample) [23].

When looking into provided diagnoses, our results also replicate other international studies [21]. We found delirium (30.8\%) to be the most common diagnosis. Similarly, other studies found a high prevalence of delirium in patients on COVID-19 wards [23, 24], ranging from $26 \%$ [22] to $38.2 \%$ [21]. It is important to note that our sample had high rates of comorbid medical illnesses, a factor well known to predispose to the development of delirium. In hindsight, it can be hypothesized that delirium develops at increased rates during COVID-19 and that physicians should more rigorously screen for it [25, 26].

Furthermore, the mortality rate in our sample was high, with intubation, as expected, identified as a significant risk factor. Other relevant risk factors include age, medical comorbidities, and a diagnosis of delirium [27, 28]. This is of relevance as CLP, oftentimes, is approached for difficult extubation; this may particularly occur secondary to agitation in the setting of hyperactive delirium [29]. Delirium is known to be a negative prognostic predictor of hospitalization [30]. Studies done at the start of the pandemic showed that delirium in elderly patients with COVID-19 infection was, in fact, strongly associated with in-hospital mortality [26,31]. Similar more recent studies confirmed that patients with COVID-19 diagnosed with delirium have a more severe infection, longer hospital stay, more admissions and transfers to intensive care units, difficult weaning, and subsequent higher mortality rates during their hospitalization [21, 23]. In one study, one-quarter of patients with COVID-19 died approximately one week after the onset of delirium [23]. Collaborative efforts should, therefore, target early and aggressive delirium treatment, with the goal at the very least of shortening its duration if not resolving it. 
One should keep in mind that the use of antipsychotics to treat delirium remains controversial and can be another risk factor for increased mortality. A recent randomizedcontrolled trial showed that the use of haloperidol or ziprasidone, compared to placebo, in patients with acute respiratory failure or shock and hypoactive or hyperactive delirium in the intensive care unit did not significantly alter one- or three-month survival [32]. Despite a systematic review and meta-analysis found no differences in outcomes of delirium when using antipsychotics, some of the included trials reported more frequent potentially harmful cardiac effects with antipsychotic use [33]. Notably, in our sample, one patient with hyperactive delirium responded to valproic acid. As the management of delirium in individuals with COVID-19 infection has variations across the globe [34], there is a dire need to develop guidelines that ensure best clinical practices in this vulnerable group. Future studies should also explore alternative treatment options, such as valproic acid [35], in case antipsychotics fail.

Anxiety and panic symptoms were also commonly observed on the consultation service. One of the earliest cross-sectional surveys of COVID-19 inpatients in two isolation wards in Wuhan found that, of 85 participants, $38.8 \%$ had symptoms of anxiety [36]. A consultation-liaison service in Morocco identified anxiety symptoms in two-third of hospitalized infected patients [37]. In the current study, the consults for anxiety required a psychological intervention, more commonly so than on regular consultation-liaison floors, focusing on breathing exercises and relaxation techniques. Our service found these tools, employed to help with "difficulty breathing" and forgetting how to "normally breathe", to be a cornerstone in the patients' treatment. This is not surprising as a strong association between post-COVID-19 fatigue and anxiety, with no associated symptoms of autonomic dysfunction, was recently reported [38]. Many post-COVID-19 patients continue to experience panic-like symptoms in the post-acute period, including dysfunctional breathing and palpitations, which typically become superimposed with - and sometimes difficult to differentiate from - other respiratory organic symptoms [39]. As such, these patients should receive close follow-up and an early tailored intervention combining pulmonary rehabilitation with psychological support [39, 40]. Mindfulness and diaphragmatic breathing exercises are particularly beneficial in this population, mainly when conducted before or during occupational and physical therapy sessions [41]. Yogic breathing was also suggested to be helpful $[42,43]$.

Suicidality, as assessed by the CLP team, was alarmingly present in $38.5 \%$ of cases. Interestingly, at the beginning of the pandemic, several mental health experts warned of a possible increase in suicide, describing it as a "tsunami of suicide", "dual pandemic of suicide and COVID-19", and "suicide mortality and COVID-19: a perfect storm" [44]. Multiple studies looked into changes in suicide rates following the pandemic. One study assessing the early effects of the COVID-19 pandemic in 21 high- and middle-income countries found that suicide rates were unchanged or even declined [45]. A systematic review looking at COVID-19-related suicide trends in Bangladesh found the prevalence of suicidal ideations to range between 5-19\% and to increase as the pandemic progressed [46]. Another study found that the risk of COVID-19-related suicide increased within the first week of diagnosis, particularly during the acute phase while receiving treatment in a hospital [47]. This sheds light on the possible difference in suicide trends according to the phase of illness, namely between the acute phase of the infection and the post-COVID-19 phase. In our study, the high prevalence of suicidality emphasizes the need for a diligent suicide risk assessment in post-COVID-19 patients. Symptoms of psychiatric, neurological, and physical illnesses, as well as inflammatory damage to the brain in individuals with post-COVID-19 syndrome, might synergistically increase suicidal ideations and behaviors 
in this population [48]. Understanding the role of these different factors can help develop appropriately tailored interventions.

An important differential diagnosis in our study was serotonin syndrome. Our two cases of serotonin syndrome, initially consulted on to rule out agitation in the setting of delirium, were prescribed several medications that increased their risk of the illness (fentanyl, linezolid, ondansetron, and selective serotonin reuptake inhibitors). Recently, serotonin syndrome was described in two patients with COVID-19 infection who received several medications with additive serotoninergic activity [49]. Zaid et al. showed that platelets are potentially hyperactivated in individuals with COVID-19, leading to increased plasma serotonin levels [50]. This was particularly noted in patients with COVID-19 experiencing diarrhea [51]. This highlights the importance of keeping a broad differential for agitation in the setting of COVID-19 infection, particularly when patients are receiving multiple serotoninergic medications, as management in the case of serotonin syndrome would diverge from standard agitation treatment guidelines.

To note, one patient in our sample required stimulants for the management of postCOVID-19 brain fog and fatigue. Several emerging reports described a new and common entity of "long haulers", where patients experience brain fog, fatigue, cognitive changes, and poor concentration among other symptoms months following the resolution of the infection $[52,53]$. The patient in our study responded to atomoxetine, which goes along with the results of a case series that reported modafinil, another stimulant, as an avenue to combat fatigue and maintain wakefulness in patients with COVID-19 infection [54].

This study has many limitations. First, it has a sample size limiting the power of the statistical analysis. Recruitment was restricted to one institution and individuals in the acute and post-acute periods of COVID-19 infection. Therefore, results cannot be generalized and should be carefully interpreted. Also, we did not compare our participants to those on the post-COVID-19 unit who did not have CLP on board. Future studies looking into this would help identify at-risk individuals who would benefit from a psychiatry consultation.

To conclude, hospitalized individuals recovering from COVID-19 infection are at risk of developing psychiatric symptoms and disorders. Diligent screening and appropriate referral to the CLP team are essential. Having a tailored approach to this category of patients is also necessary, including checking for less common differentials and providing appropriate and timely psychological interventions. Subsequent outpatient monitoring should be kept in mind as these individuals could be at increased risk of suffering from long-term psychiatric sequelae.

Funding This research did not receive any specific grant from funding agencies in the public, commercial, or not-for-profit sectors.

Availability of Data and Material (data transparency) Available upon request.

Code Availability (software code or custom code) Available upon request.

\section{Declarations}

Ethics Approval This retrospective chart review study involving human participants was in accordance with the ethical standards of the institutional and national research committee and with the 1964 Helsinki Declaration and its later amendments or comparable ethical standards. The Human Investigation Committee (IRB) of the American University of Beirut Medical Center (AUBMC) approved this study.

Consent to Participate Not applicable. 
Consent for Publication Not applicable.

Conflict of Interest/Competing Interests The authors declare that they have no conflicts of interest.

\section{References}

1. Wang S, Wen X, Dong Y, Liu B, Cui M. Psychological influence of coronovirus disease 2019 (COVID-19) pandemic on the general public, medical workers, and patients with mental disorders and its countermeasures. Psychosomatics. 2020;61(6):616-24. https://doi.org/10.1016/j.psym.2020.05.005.

2. Vindegaard N, Benros ME. COVID-19 pandemic and mental health consequences: Systematic review of the current evidence. Brain Behav Immun. 2020;89:531-42. https://doi.org/10.1016/j.bbi.2020.05. 048.

3. Wang C, Pan R, Wan X, Tan Y, Xu L, Ho CS, Ho RC. Immediate psychological responses and associated factors during the initial stage of the 2019 coronavirus disease (COVID-19) epidemic among the general population in China. Int J Environ Res Public Health 2020;17(5). https://doi.org/10.3390/ijerph17051729.

4. Lai J, Ma S, Wang Y, Cai Z, Hu J, Wei N, Wu J, Du H, Chen T, Li R, Tan H, Kang L, Yao L, Huang M, Wang H, Wang G, Liu Z, Hu S. Factors associated with mental health outcomes among health care workers exposed to coronavirus disease 2019. JAMA Netw Open. 2020;3(3):e203976-e203976. https://doi.org/10.1001/jamanetworkopen.2020.3976.

5. Nalleballe K, Reddy Onteddu S, Sharma R, Dandu V, Brown A, Jasti M, Yadala S, Veerapaneni K, Siddamreddy S, Avula A, Kapoor N, Mudassar K, Kovvuru S. Spectrum of neuropsychiatric manifestations in COVID-19. Brain Behav Immun. 2020;88:71-4. https://doi.org/10.1016/j.bbi.2020.06.020.

6. Mazza MG, De Lorenzo R, Conte C, Poletti S, Vai B, Bollettini I, Melloni EMT, Furlan R, Ciceri F, Rovere-Querini P, Benedetti F. Anxiety and depression in COVID-19 survivors: Role of inflammatory and clinical predictors. Brain Behav Immun. 2020;89:594-600. https://doi.org/10.1016/j.bbi.2020.07. 037.

7. Sher L. The impact of the COVID-19 pandemic on suicide rates. QJM. 2020;113(10):707-12. https:// doi.org/10.1093/qjmed/hcaa202.

8. Rogers JP, Chesney E, Oliver D, Pollak TA, McGuire P, Fusar-Poli P, Zandi MS, Lewis G, David AS. Psychiatric and neuropsychiatric presentations associated with severe coronavirus infections: a systematic review and meta-analysis with comparison to the COVID-19 pandemic. Lancet Psychiatry. 2020;7(7):611-27. https://doi.org/10.1016/s2215-0366(20)30203-0.

9. Sheehy LM. Considerations for postacute rehabilitation for survivors of COVID-19. JMIR Public Health Surveill. 2020;6(2): e19462. https://doi.org/10.2196/19462.

10. Xiang YT, Yang Y, Li W, Zhang L, Zhang Q, Cheung T, Ng CH. Timely mental health care for the 2019 novel coronavirus outbreak is urgently needed. Lancet Psychiatry. 2020;7(3):228-9. https://doi. org/10.1016/s2215-0366(20)30046-8.

11. Brooks SK, Webster RK, Smith LE, Woodland L, Wessely S, Greenberg N, Rubin GJ. The psychological impact of quarantine and how to reduce it: rapid review of the evidence. Lancet. 2020;395(10227):912-20. https://doi.org/10.1016/s0140-6736(20)30460-8.

12. Chaves C, Castellanos T, Abrams M, Vazquez C. The impact of economic recessions on depression and individual and social well-being: the case of Spain (2006-2013). Soc Psychiatry Psychiatr Epidemiol. 2018;53(9):977-86. https://doi.org/10.1007/s00127-018-1558-2.

13. Mao L, Jin H, Wang M, Hu Y, Chen S, He Q, Chang J, Hong C, Zhou Y, Wang D, Miao X, Li Y, Hu B. Neurologic manifestations of hospitalized patients with coronavirus disease 2019 in Wuhan, China. JAMA Neurology. 2020;77(6):683-90. https://doi.org/10.1001/jamaneurol.2020.1127.

14. Mascolo A, Berrino PM, Gareri P, Castagna A, Capuano A, Manzo C, Berrino L. Neuropsychiatric clinical manifestations in elderly patients treated with hydroxychloroquine: a review article. Inflammopharmacology. 2018;26(5):1141-9. https://doi.org/10.1007/s10787-018-0498-5.

15. Wu Y, Xu X, Chen Z, Duan J, Hashimoto K, Yang L, Liu C, Yang C. Nervous system involvement after infection with COVID-19 and other coronaviruses. Brain Behav Immun. 2020;87:18-22. https:// doi.org/10.1016/j.bbi.2020.03.031.

16. Baig AM, Khaleeq A, Ali U, Syeda H. Evidence of the COVID-19 virus targeting the CNS: tissue distribution, host-virus interaction, and proposed neurotropic mechanisms. ACS Chem Neurosci. 2020;11(7):995-8. https://doi.org/10.1021/acschemneuro.0c00122. 
17. Kotfis K, Williams Roberson S, Wilson JE, Dabrowski W, Pun BT, Ely EW. COVID-19: ICU delirium management during SARS-CoV-2 pandemic. Crit Care. 2020;24(1):176. https://doi.org/10.1186/ s13054-020-02882-x.

18. Funk MC, Beach SR, Shah SB, Boland R. Consultation-liaison psychiatry in the age of COVID-19: reaffirming ourselves and our worth. Psychosomatics. 2020;61(5):571-2. https://doi.org/10.1016/j. psym.2020.04.013.

19. Horn M, Granon B, Vaiva G, Fovet T, Amad A. Role and importance of consultation-liaison psychiatry during the Covid-19 epidemic. J Psychosom Res. 2020;137:110214-110214. https://doi.org/10. 1016/j.jpsychores.2020.110214.

20. Aguirre-Chang G, Trujillo A. Post-acute and chronic COVID. Towards a consensus on the definitions for the persistent symptoms of COVID. ResearchGate. 2020.

21. Turan Ş, Poyraz BÇ, Aksoy Poyraz C, Demirel ÖF, Tanrı̈ver Aydın E, Uçar Bostan B, Demirel Ö, Ali RK. Characteristics and outcomes of COVID-19 inpatients who underwent psychiatric consultations. Asian J Psychiatr. 2021;57:102563-102563. https://doi.org/10.1016/j.ajp.2021.102563.

22. Iqbal Y, Al Abdulla MA, Albrahim S, Latoo J, Kumar R, Haddad PM. Psychiatric presentation of patients with acute SARS-CoV-2 infection: a retrospective review of 50 consecutive patients seen by a consultation-liaison psychiatry team. BJPsych Open. 2020;6(5):e109-e109. https://doi.org/10.1192/ bjo. 2020.85 .

23. Arbelo N, López-Pelayo H, Sagué M, Madero S, Pinzón-Espinosa J, Gomes-da-Costa S, Ilzarbe L, Anmella G, Llach C-D, Imaz M-L, Cámara M-M, Pintor L. Psychiatric clinical profiles and pharmacological interactions in COVID-19 inpatients referred to a consultation liaison psychiatry unit: a crosssectional study. Psychiatr Q. 2021. https://doi.org/10.1007/s11126-020-09868-6.

24. Jhanwar S, Krishnan V, Rohilla J. Consultation-liaison psychiatry during COVID-19 lockdown: a retrospective chart review. Cureus. 2020;12(10):e11048-e11048. https://doi.org/10.7759/cureus.11048.

25. O'Hanlon S, Inouye SK. Delirium: a missing piece in the COVID-19 pandemic puzzle. Age Ageing. 2020;49(4):497-8. https://doi.org/10.1093/ageing/afaa094.

26. Garcez FB, Aliberti MJR, Poco PCE, Hiratsuka M, Takahashi SdF, Coelho VA, Salotto DB, Moreira MLV, Jacob-Filho W, Avelino-Silva TJ. Delirium and adverse outcomes in hospitalized patients with COVID-19. J Am Geriatr Soc. 2020;68(11):2440-6. https://doi.org/10.1111/jgs.16803.

27. Incerti D, Rizzo S, Li X, Lindsay L, Yau V, Keebler D, Chia J, Tsai L. Risk factors for mortality among hospitalized patients with COVID-19. medRxiv:2020.2009.2022.20196204. 2020. https://doi. org/10.1101/2020.09.22.20196204.

28. Schuurmans MJ, Duursma SA, Shortridge-Baggett LM. Early recognition of delirium: review of the literature. J Clin Nurs. 2001;10(6):721-9. https://doi.org/10.1046/j.1365-2702.2001.00548.x.

29. Dupuis S, Brindamour D, Karzon S, Frenette AJ, Charbonney E, Perreault MM, Bellemare P, Burry L, Williamson DR. A systematic review of interventions to facilitate extubation in patients difficult-towean due to delirium, agitation, or anxiety and a meta-analysis of the effect of dexmedetomidine. Can J Anaesth. 2019;66(3):318-27. https://doi.org/10.1007/s12630-018-01289-1.

30. Inouye SK, Westendorp RGJ, Saczynski JS. Delirium in elderly people. Lancet (London, England). 2014;383(9920):911-22. https://doi.org/10.1016/S0140-6736(13)60688-1.

31. Marengoni A, Zucchelli A, Grande G, Fratiglioni L, Rizzuto D. The impact of delirium on outcomes for older adults hospitalised with COVID-19. Age Ageing. 2020;49(6):923-6. https://doi.org/10.1093/ ageing/afaa189.

32. Girard TD, Exline MC, Carson SS, Hough CL, Rock P, Gong MN, Douglas IS, Malhotra A, Owens RL, Feinstein DJ, Khan B, Pisani MA, Hyzy RC, Schmidt GA, Schweickert WD, Hite RD, Bowton DL, Masica AL, Thompson JL, Chandrasekhar R, Pun BT, Strength C, Boehm LM, Jackson JC, Pandharipande PP, Brummel NE, Hughes CG, Patel MB, Stollings JL, Bernard GR, Dittus RS, Ely EW. Haloperidol and ziprasidone for treatment of delirium in critical illness. N Engl J Med. 2018;379(26):2506-16. https://doi. org/10.1056/NEJMoa1808217.

33. Oh ES, Needham DM, Nikooie R, Wilson LM, Zhang A, Robinson KA, Neufeld KJ. Antipsychotics for Preventing delirium in hospitalized adults. Ann Intern Med. 2019;171(7):474-84. https://doi.org/10.7326/ M19-1859.

34. Ojeahere MI, de Filippis R, Ransing R, Karaliuniene R, Ullah I, Bytyçi DG, Abbass Z, Kilic O, Nahidi M, Hayatudeen N, Nagendrappa S, Shoib S, Jatchavala C, Larnaout A, Maiti T, Ogunnubi OP, El Hayek S, Bizri M, Schuh Teixeira AL, Pereira-Sanchez V, Pinto da Costa M. Management of psychiatric conditions and delirium during the COVID-19 pandemic across continents: lessons learned and recommendations. Brain, Behavior, \& Immunity - Health. 2020;9: 100147. https://doi.org/10.1016/j.bbih.2020.100147.

35. Sher Y, Miller Cramer AC, Ament A, Lolak S, Maldonado JR. Valproic acid for treatment of hyperactive or mixed delirium: rationale and literature review. Psychosomatics. 2015;56(6):615-25. https://doi.org/10. 1016/j.psym.2015.09.008. 
36. Hu Y, Chen Y, Zheng Y, You C, Tan J, Hu L, Zhang Z, Ding L. Factors related to mental health of inpatients with COVID-19 in Wuhan, China. Brain Behav Immun. 2020;89:587-93. https://doi.org/10.1016/j. bbi.2020.07.016.

37. Benjelloun R, Otheman Y, El Kettani C. Consultation liaison psychiatry for COVID-19 inpatients: A novel care delivery program in Morocco. Curr Psychol. 2020. https://doi.org/10.1007/s12144-020-01200-6.

38. Townsend L, Moloney D, Finucane C, McCarthy K, Bergin C, Bannan C, Kenny R-A. Fatigue following COVID-19 infection is not associated with autonomic dysfunction. PLoS One. 2021;16(2): e0247280. https://doi.org/10.1371/journal.pone.0247280.

39. Kurtaiş Aytür Y, Köseoğlu BF, Özyemişçi Taşkıran Ö, Ordu-Gökkaya NK, Ünsal Delialioğlu S, Sonel Tur B, Sarıkaya S, Şirzai H, Tekdemir Tiftik T, Alemdaroğlu E, Ayhan FF, Duyur Çakıt BD, Genç A, Gündoğdu İ, Güzel R, Demirbağ Karayel D, Bilir Kaya B, Öken Ö, Özdemir H, Soyupek F, Tıkız C. Pulmonary rehabilitation principles in SARS-COV-2 infection (COVID-19): A guideline for the acute and subacute rehabilitation. Turk J Phys Med Rehabil. 2020;66(2):104-20. https://doi.org/10.5606/tftrd.2020. 6444.

40. Hayes JP. Considering the long-term respiratory effects of Covid-19. Occup Med (Lond):kqaa224. 2021. https://doi.org/10.1093/occmed/kqaa224.

41. Jaywant A, Vanderlind WM, Boas SJ, Dickerman AL. Behavioral interventions in acute COVID-19 recovery: A new opportunity for integrated care. Gen Hosp Psychiatry. 2021;69:113-4. https://doi.org/10. 1016/j.genhosppsych.2020.07.001.

42. Rain M, Subramaniam B, Avti P, Mahajan P, Anand A. Can Yogic Breathing Techniques Like Simha Kriya and Isha Kriya Regulate COVID-19-Related Stress? Frontiers in Psychology. 2021;12 (1297). https://doi.org/10.3389/fpsyg.2021.635816.

43. Zope SA, Zope RA, Biri GA, Zope CS. Sudarshan Kriya Yoga: A Breath of Hope during COVID-19 Pandemic. Int J Yoga. 2021;14(1):18-25. https://doi.org/10.4103/ijoy.IJOY_102_20.

44. Tandon R. COVID-19 and suicide: Just the facts. Key learnings and guidance for action. Asian J Psychiatr. 2021;60:102695-102695. https://doi.org/10.1016/j.ajp.2021.102695.

45. Pirkis J, John A, Shin S, DelPozo-Banos M, Arya V, Analuisa-Aguilar P, Appleby L, Arensman E, Bantjes J, Baran A, Bertolote JM, Borges G, Brečić P, Caine E, Castelpietra G, Chang S-S, Colchester D, Crompton D, Curkovic M, Deisenhammer EA, Du C, Dwyer J, Erlangsen A, Faust JS, Fortune S, Garrett A, George D, Gerstner R, Gilissen R, Gould M, Hawton K, Kanter J, Kapur N, Khan M, Kirtley OJ, Knipe D, Kolves K, Leske S, Marahatta K, Mittendorfer-Rutz E, Neznanov N, Niederkrotenthaler T, Nielsen E, Nordentoft M, Oberlerchner H, O'Connor RC, Pearson M, Phillips MR, Platt S, Plener PL, Psota G, Qin P, Radeloff D, Rados C, Reif A, Reif-Leonhard C, Rozanov V, Schlang C, Schneider B, Semenova N, Sinyor M, Townsend E, Ueda M, Vijayakumar L, Webb RT, Weerasinghe M, Zalsman G, Gunnell D, Spittal MJ. Suicide trends in the early months of the COVID-19 pandemic: an interrupted time-series analysis of preliminary data from 21 countries. The Lancet Psychiatry. 2021;8(7):579-88. https://doi.org/10.1016/S2215-0366(21)00091-2.

46. Mamun MA. Suicide and Suicidal Behaviors in the Context of COVID-19 Pandemic in Bangladesh: A Systematic Review. Psychol Res Behav Manag. 2021;14:695-704. https://doi.org/10.2147/PRBM.S315760.

47. Sripad MN, Pantoji M, Gowda GS, Ganjekar S, Reddi VSK, Math SB. Suicide in the context of COVID19 diagnosis in India: Insights and implications from online print media reports. Psychiatry Res. 2021;298:113799-113799. https://doi.org/10.1016/j.psychres.2021.113799.

48. Sher L. Post-COVID syndrome and suicide risk Qjm. 2021;114(2):95-8. https://doi.org/10.1093/qjmed/ hcab007.

49. Mas Serrano M, Pérez-Sánchez JR, Portela Sánchez S, De La Casa-Fages B, Mato Jimeno V, Pérez Tamayo I, Grandas F. Serotonin syndrome in two COVID-19 patients treated with lopinavir/ritonavir. J Neurol Sci. 2020;415:116944-116944. https://doi.org/10.1016/j.jns.2020.116944.

50. Zaid Y, Puhm F, Allaeys I, Naya A, Oudghiri M, Khalki L, Limami Y, Zaid N, Sadki K, Ben El Haj R, Mahir W, Belayachi L, Belefquih B, Benouda A, Cheikh A, Langlois MA, Cherrah Y, Flamand L, Guessous F, Boilard E. Platelets can associate with SARS-Cov-2 RNA and are hyperactivated in COVID-19. Circ Res. 2020;127(11):1404-18. https://doi.org/10.1161/circresaha.120.317703.

51. Ha S, Jin B, Clemmensen B, Park P, Mahboob S, Gladwill V, Lovely FM, Gottfried-Blackmore A, Habtezion A, Verma S, Ro S. Serotonin is elevated in COVID-19-associated diarrhoea. Gut:gutjnl-2020-323542. 2021. https://doi.org/10.1136/gutjnl-2020-323542.

52. Nordvig A, Noble J. Post-COVID Brain Fog: A patient registry and cross-disciplinary approach to characterization, treatment, and etiology. (4288). Neurology. 2021;96(15 Supplement):4288.

53. Graham EL, Clark JR, Orban ZS, Lim PH, Szymanski AL, Taylor C, DiBiase RM, Jia DT, Balabanov R, Ho SU, Batra A, Liotta EM, Koralnik IJ. Persistent neurologic symptoms and cognitive dysfunction in non-hospitalized Covid-19 "long haulers." Annals of Clinical and Translational Neurology. 2021;8(5):1073-85. https://doi.org/10.1002/acn3.51350. 
54. Amer M, Bawazeer M, Butt AS, Dahhan TI, Kseibi E, Jamil MG. Modafinil for wakefulness in the critical care units: a literature review and case series including COVID-19 patients at a tertiary care saudi hospital. 2021. medRxiv:2021.2002.2011.21250832. https://doi.org/10.1101/2021.02.11.21250832.

Publisher's Note Springer Nature remains neutral with regard to jurisdictional claims in published maps and institutional affiliations.

Samer El Hayek Dr.El Hayek is an addiction psychiatry fellow at Jackson Health System - University of Miami, Florida. He earned his medical degree and completed his residency training in psychiatry at the American University of Beirut Medical Center. Dr. El Hayek is a member of the Early-Career-Psychiatrists Section of the World Psychiatric Association. He founded the Early-Career-Psychiatrists and Residents Section of the Lebanese Psychiatric Society and chaired it for the past 2 years. Dr. El Hayek has more than thirty five peer-reviewed publications, including several book chapters. He is the recipient of many national and international awards. In 2019, he was awarded the Early-Career-Psychiatrists Award and Certificate of Appreciation and the Asian Federation of Psychiatric Associations Fellowship Award for Young Psychiatrists.

Ghida Kassir Dr. Kassir completed her medical degree at theAmerican University of Beirut and is currently a fourth year psychiatryresident at the American University of Beirut Medical Center. She isparticularly interested in consult-liaison psychiatry. Her main interest duringthe pandemic was studying the effect of COVID-19 on the mental health ofvulnerable populations including university students and medical professionals.

Hussein Zalzale Dr. Zalzale is a recent medical graduate fromthe American University of Beirut. He is interested in psychiatry andpsychotherapy, specifically parts relating to trauma.

Jairo Gonzalez Dr. Gonzalez is a Colombian certifiedpsychiatrist with a Master degree in Mental Health Research. He currently worksat the UR Center for Mental Health - CERSAME (School of Medicine and HealthSciences, Universidad del Rosario) and Clínica Nuestra Señora de la Paz inBogotá, Colombia. Jairo does research in Psychiatry at Barcelona ClinicSchizophrenia Unit (Neurosciences Institute, Hospital Clínic Barcelona -Universitat de Barcelona). He is a member of Early Career Psychiatrists Sectionof World Psychiatric Association, Centro de Investigaciones del SistemaNervioso - CISNE and Latin American Network for the Study of Early Psychosis -ANDES.

Maya Bizri Dr. Bizri holds a psychosomatic medicine fellowship from the CCF and an MPH from Tufts. She's an assistant professor at the American University of Beirut Medical Center and founder/director of the Consultation Liaison psychiatry service as well as the psycho-oncology program. Her interests during the pandemic were redirected towards novel methods in detection and management of delirium and psychiatric morbidities in hospitalized patients. 